\title{
Effect of Clover Phyllody Virus on Nodulation of White Clover (Trifolium repens) by Rhizobium trifolii in Soil
}

\author{
By H. U. JOSHI AND A. J. H. CARR \\ Welsh Plant Breeding Station, Aberystwyth \\ (Accepted for publication 2 June 1967)
}

SUMMARY

\begin{abstract}
When grown in sterilized soil inoculated with an effective Rhizobium strain which produced many large pigmented nodules on virus-free plants, plants infected with clover phyllody virus (CPV) produced mainly small white nodules characteristic of an ineffective reaction. Mainly small nodules were also given by virus-free plants exposed to mixtures of effective and naturally ineffective Rhizobium strains, which separately gave predominantly large and predominantly small nodules, respectively, indicating that the ineffective strain had a high competitive ability for invasion sites on the roots.

When the CPV-infected plants were removed and fresh seed sown in the soil, germination was poor and the seedlings produced predominantly small nodules. The rhizobia seemed modified to a less effective form which produced mainly small nodules and competed successfully with unmodified bacteria. Yields of clover in swards may therefore be decreased by CPV infection, not only through a direct effect on plant growth but also through effects on the soil Rhizobium population, and hence on the growth of infected plants and neighbouring virus-free plants.
\end{abstract}

\section{INTRODUCTION}

Joshi, Carr \& Jones (1967) reported that white clover plants infected with the persistent jassid-transmitted clover phyllody virus CPV ( = strawberry green-petal virus; Frazier \& Posnette, I957; Chiykowski, I962; Posnette \& Ellenberger, I963), produced a high proportion of small and non-pigmented nodules characteristic of decreased effectiveness in fixing nitrogen when inoculated in agar culture with a normally highly effective strain of Rhizobium trifolii derived from a single bacterial colony. Rhizobia transferred from infected to healthy plants again elicited this partially ineffective response, possibly because of a genetic change induced in the bacterium and not because it acted as a vector of the virus.

Although the experiments were made with artificial media, our earlier unpublished observations and those of Vanderveken (1964) suggest that similar effects occur under natural soil conditions. An important practical point to consider is whether, when released into the soil, rhizobia induced to partial ineffectiveness through having invaded virus-infected plants compete better than fully effective ones for invasion sites on the roots of healthy hosts, with ensuing general decrease of the efficiency of nitrogen fixation throughout the sward. Nicol \& Thornton (1942) showed that some Rhizobium strains were better competitors than others, and although their competitive ability was generally independent of the degree of effectiveness, certain strains were found to be both ineffective and highly competitive. Fred, Baldwin \& McCoy (1932) 
demonstrated that plants already infected with one Rhizobium strain resisted infection by another strain to a greater degree than un-nodulated plants. Nutman (1952) showed that a substance which inhibited further nodulation was produced in the nodule apex.

The results of experiments comparing the growth and nodulation of CPV-infected and healthy white clover, grown consecutively in sterilized soil inoculated with effective and ineffective strains of Rhizobium both separately and together, are reported in this paper. Throughout, the term 'healthy' implies only freedom from infection with CPV.

\section{METHODS}

Wooden boxes $18 \times 12 \times 8$ in. deep were treated with $2 \%$ formaldehyde solution to destroy naturally occurring rhizobia, and were filled from the same batch of John Innes no. I compost sterilized previously by autoclaving for $90 \mathrm{~min}$. at $12 \mathrm{I}^{\circ}$. They were then allowed to stand for 2 weeks before inoculation. An effective w 4 culture and an ineffective w 22 culture of Rhizobium trifolii, both from the W.P.B.S. collection and each re-isolated recently from a single colony, were streaked on plates of yeast mannitol agar. Organisms were removed from Io-day plates by scraping the surface with a smooth-edged microscope slide, and transferred to demineralized water. Following homogenization in a blender, the concentration of the two suspensions, as measured by their turbidity in an EEL nephelometer, was equalized by adding a further quantity of demineralized water. A $40 \mathrm{ml}$. portion was sprayed from a fine atomizer on to the separated top inch of soil removed from each box, with frequent mixing, and the soil was then replaced in an even layer. Eight boxes received the effective w 4 strain, four the ineffective $\mathrm{W} 22$, and four a mixture of $20 \mathrm{ml}$. W 4 and $20 \mathrm{ml}$. W 22 suspension.

Young actively growing stolon apices, each bearing a single apical growing point and an incipient root not yet broken through the outer tissues, were detached from plants of two white clover clones (nos. 33, 45), selected from the variety S. Ioo on the basis of their marked reaction to CPV. Some of these plants were healthy and others infected with our moderately virulent CPV isolate F. After thorough washing in sterile water they were planted in the boxes, each genotype occupying alternate rows of six plants and each box receiving 24 cuttings. Four of the eight boxes inoculated with the effective Rhizobium strain were planted with healthy and four with CPV-infected cuttings. Boxes containing the ineffective strain and those with a mixture of effective and ineffective strains were all planted with healthy cuttings. The boxes were arranged in a $4 \times 4$ Latin square under mist propagation for Io days, and were then removed in the same order to the glasshouse bench. Healthy cuttings in a box without added rhizobia had very few nodules by the end of the experimental period, indicating the adequacy of the sterilization procedures. Data from plants in this box did not feature in the main analyses. At the end of June, when this first half of the experiment had run for 3 months, plants were harvested, their shoot dry-weight and root nodulation recorded.

Immediately after harvest, all roots were separated from shoots, chopped into small pieces and returned to the soil of their respective boxes with thorough mixing of the upper layer, so that rhizobia present in the nodules would be released as the roots decayed. Each box was then sown with surface-sterilized seeds of the white clover variety $\mathrm{S}$. 100, with the intention to thin the number of seedlings down to 24 . How- 
ever, germination was abnormally low in boxes which had previously contained CPVinfected plants, and these boxes were resown after 6 days with excess seed. Although germination was again poor, there were now sufficient plants to enable thinning to the 24 required. Because the weather was now favourable, all boxes were moved outside for this second half of the experiment until harvest in mid-September.

At each harvest, all plants from each box were separated into root and shoot, the shoot portions were oven-dried at $80^{\circ}$ for $6 \mathrm{hr}$ and the mean dry weight per plant recorded. Root portions from four randomly selected plants were examined in fresh condition and the mean number of nodules per plant in each of the visually estimated classes (large, medium, small) determined. The roots were then air-dried at normal laboratory temperature $\left(\mathrm{I} 7^{\circ}\right)$ for 2 days and their weight recorded, so that the nodule data could also be expressed as the number of nodules/g. root. All data were subjected to analysis of variance; the statistical technique used for the nodule counts was such that the interaction of treatment with nodule size was a function of the effect of treatment on the frequency of distribution over the three classes of nodules.

\section{RESULTS}

\section{Growth and nodulation of uninfected and CPV-infected cuttings}

Immediately before harvesting the plants of the first half of the experiment there were marked differences in growth between the four treatments. Healthy plants inoculated with the effective Rhizobium strain were robust and dark green; those inoculated with a mixture of effective and ineffective rhizobia were smaller and paler green; those with ineffective rhizobia only were smaller still and distinctly yellowish, giving an impression of nitrogen starvation. CPV-infected plants were, as usual, very small, with chlorotic leaves. The healthy plants with effective rhizobia had produced large, mostly elongated, pink or pinkish-white nodules confined mainly to the upper root region, typical of an effective reaction. Healthy plants with ineffective rhizobia had abundant small white ineffective nodules distributed over the entire root, while those with the mixture of effective and ineffective rhizobia also bore many small ineffective type nodules and the few larger nodules produced were confined mainly to the lateral roots. CPV-infected plants, although inoculated with the effective Rhizobium strain, nevertheless bore mainly small round white ineffective-type nodules, although a few were larger and pinkish white.

The analyses of variance showed that the four treatments differed significantly in shoot dry weight $(P=0.0 \mathrm{I})$, and total number of nodules per plant $(P=0.05)$ and per g. air-dried root $(P=0 \cdot 0 \mathrm{I})$. The effect of the four treatments on nodule size distribution was highly significant $(P=0.00 \mathrm{I})$ both per plant and per g. root.

Figure I presents the mean data for shoot dry weight and for nodule number and size distribution which confirmed the visual observations. The histograms show a close similarity between the nodules on a per unit weight of root basis, indicating a constancy of root development for all except the CPV-infected plants, and that most of the variation was in the degree of nodulation. However, CPV-infected plants had smaller roots than healthy ones; hence the smaller differential here between the per plant and per unit root weight data. There was a significant correlation between shoot dry weight and the number of large nodules produced $(r=0.66 ; P=0.0 \mathrm{I})$ by either CPVinfected or healthy plants. 


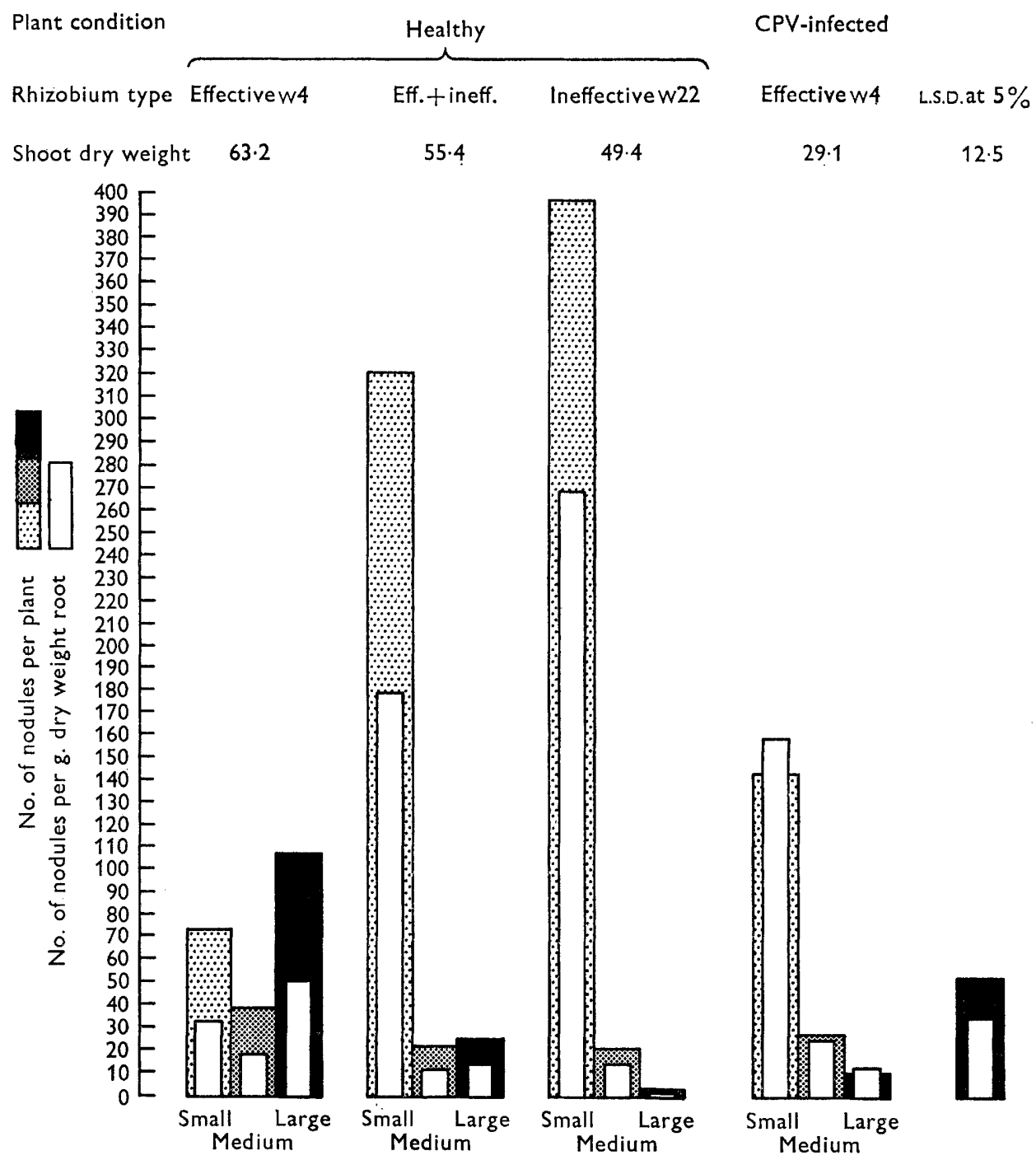

Fig. I. Mean dry weight and nodulation characteristics of healthy and CPV-infected clones of white clover grown in soil inoculated with effective w 4 and ineffective w 22 strains of Rhizobium trifolii.

\section{Growth and nodulation of healthy seedling plants raised in soil}

from the previous treatments

Plate I, shows the growth and general vigour of the seedling plants in the four different treatments immediately before harvest. Those raised in boxes previously containing healthy cuttings nodulated by the effective Rhizobium strain were clearly the most vigorous, the darkest green, and had begun to flower; those in the healthy/ ineffective boxes were stunted, pale yellowish green, and very few had reached the flowering stage. Seedling plants in the healthy/mixed effective and ineffective boxes 
were intermediate between these extremes in growth and colour, although there was considerably more plant-to-plant variation; none of these plants had flowered. Plants in boxes which had previously contained CPV-infected cuttings in combination with the effective Rhizobium strain were little better in either growth or colour than those in the healthy/ineffective boxes and none had reached the flowering stage.

\begin{tabular}{|c|c|c|c|c|c|}
\hline \multirow{2}{*}{$\begin{array}{l}\text { Initial plant condition } \\
\text { Initial Rhizobium type }\end{array}$} & \multicolumn{3}{|c|}{ Healthy } & \multicolumn{2}{|l|}{ CPV-infected } \\
\hline & Effective w4 & Eff. +ineff. & Ineffective $w 22$ & Effective $w 4$ & L.S.D.at $5 \%$ \\
\hline Percentage germination & 84.7 & 70.9 & 68.8 & 22.9 & $31 \cdot 3$ \\
\hline Shoot dry weight & 39.1 & $22 \cdot 2$ & $6 \cdot 3$ & 10.8 & $11 \cdot 3$ \\
\hline
\end{tabular}
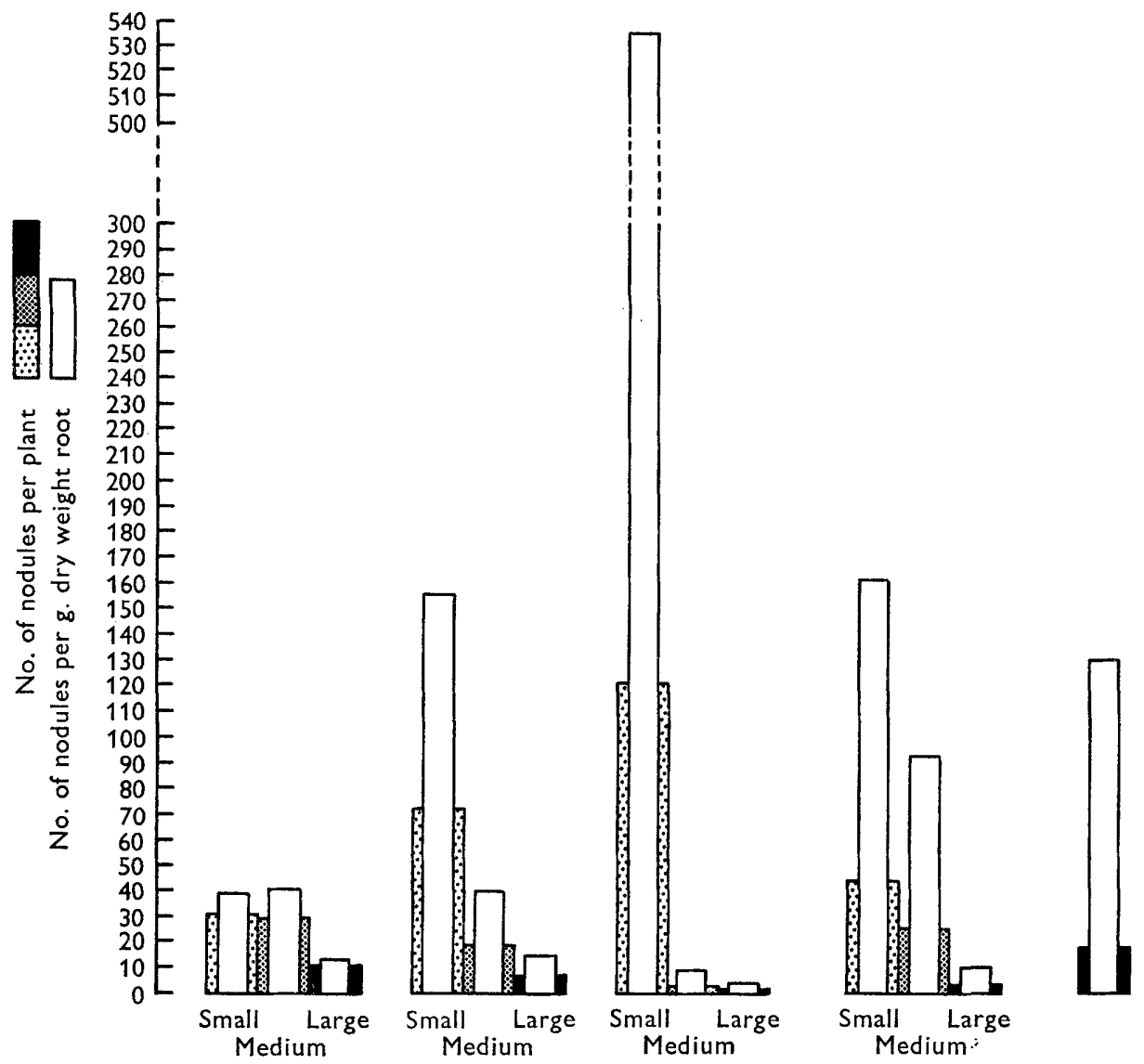

Fig. 2. Mean percentage germination, dry weight and nodulation characteristics of healthy white clover plants reared from seed in soil previously inoculated with effective $\mathrm{w} 4$ and ineffective w 22 strains of Rhizobium trifolii, and in which healthy and CPV-infected white clover clones were grown.

The analyses of variance showed that previous treatment had influenced significantly the shoot dry weight $(P=0.0 \mathrm{I})$, the total number of nodules produced/g. airdried root $(P=0.05)$, and the distribution of nodules among the three classes (large, 
medium, small) both per plant $(P=0.00 \mathrm{I})$ and per $\mathrm{g}$. $\operatorname{root}(P=0.0 \mathrm{I})$. Differences in total number of nodules per plant just failed to reach significance at $P=0.05$. As in the first half of the experiment, the number of large nodules produced was correlated with the shoot dry weight, but with an even higher degree of significance $(r=0.9 \mathrm{I}$; $P=0.001$ ).

The mean data for shoot dry weight, percentage germination, and number of nodules of different sizes are presented in Fig. 2. The data for shoot dry weight clearly confirm the visual observations. The virus-free seedlings raised in soil that had previously contained CPV-infected cuttings in association with a normally highly effective Rhizobium strain did not yield significantly more than those in soil previously containing healthy cuttings nodulated by an ineffective strain. Figure 2 shows also that the pattern of nodulation was very similar whether calculated on a per plant or a per unit weight of root basis. However, because the seedlings were both smaller and younger than the cuttings harvested in the first half of the experiment, their root systems were smaller; hence the number of nodules per plant was generally less than the number/g. airdried root. The least differential between the per plant and per unit weight data was evident in the healthy/effective combination, due to the proportionately greater amount of root produced. Even the healthy/effective treatment did not produce the expected frequency of large nodules, because the seedlings were harvested before potentially large nodules had reached their maximum sizes. Despite this, the frequency of small nodules increased significantly from the healthy/effective, to the healthy/mixed effective and ineffective, and healthy/ineffective treatments. However, the CPV-infected/effective plants did not produce significantly more small nodules than the healthy/effective ones. The original analysis of variance did not reveal any significant difference between treatments in the production of large nodules, but a $\chi^{2}$ test of the ratio of large:medium: small nodules produced per plant showed the distribution to vary significantly between treatments $(P=0.00 \mathrm{I})$. Partitioning $\chi^{2}$ between individual comparisons showed that, although the ratio of large:medium:small nodules produced by the CPV-infected/effective treatment differed significantly from the ratios for all other treatments, and particularly from the healthy/effective combination, it approached most closely to that of the healthy/mixed effective and ineffective. Thus, the nodulation characteristics of healthy seedling plants grown in soil previously inoculated with an effective Rhizobium strain and planted with CPVinfected cuttings were very similar to those obtaining when the soil was inoculated with a mixture of effective and ineffective strains and planted originally with healthy cuttings.

\section{DISCUSSION}

These experiments show that, as in agar culture (Joshi et al. 1967), so also in soil, white clover plants infected with clover phyllody virus (CPV) produced mainly small white nodules even though nodulated by an effective strain of Rhizobium tirfolii which normally produced many large pigmented nodules. Although CPV-induced ineffectiveness did not lead to an increase in the total number of nodules per plant, as is common when a naturally ineffective Rhizobium strain is involved, this was due entirely to the poor root development of the virus-infected plants; the number of nodules per unit weight of root was greatly in excess of the number developed on healthy plants. An important criterion of effectiveness in terms of plant growth is, 
evidently, the number of large nodules produced irrespective of the number of small nodules: even in the first half of the experiment, where available soil nitrogen was undoubtedly high, a reasonably good correlation was obtained between shoot weight and the number of large nodules; and in the second half, where less soil nitrogen would have been available, the correlation was even higher.

Presumably rhizobia from the CPV-infected plants were released into the soil when the nodules decayed, and were then able to compete with the existing Rhizobium population for sites on the host roots. The suggestion is that, in the second half of the experiment, when healthy plants in soil formerly occupied by CPV-infected plants developed mainly small white nodules, the healthy plants were nodulated preferentially by rhizobia which had become modified to ineffectiveness by passage through $\mathrm{CPV}$-infected plants. This was similar to the result obtained when the effective w4 strain and the naturally ineffective w 22 strains of Rhizobium trifolii competed for nodule sites on the normal virus-free host. If this inference is correct, then it is evident that in soil as in agar culture ability to produce many large nodules is not immediately restored when previously effective rhizobia transfer from CPV-infected plants to healthy ones, and the contention of Vanderveken (1964) that it is restored is not substantiated by these results.

One factor not investigated here, which might complicate the interpretation of these results, is the changing nitrogen status of the soil with the various treatments. Although the same batch of compost was used throughout, and all treatments were presumably of equivalent nitrogen content initially, it is obvious that by the time seeds were sown at the start of the second half of the experiment the available nitrogen concentration might have varied widely between treatments. Current techniques of soil-nitrogen determination are not sufficiently critical to be of great value in this type of experiment, nor would it have been possible, even if they were, to.apportion the end-results between the various factors leading to an increase or decrease of soil-nitrogen content.

One unexplained result was the poor germination of seed in soil previously containing CPV-infected plants. It seems unlikely that this was due to a nutritional deficiency. Possibly such plants exude substances inhibitory to germination.

Clearly the hitherto unsuspected effect of CPV on nodulation even of healthy clover plants in the sward, in addition to the more direct action of virus on host, might well be responsible for a considerable and largely non-measurable decrease of yield. The possibility of amelioration, not only through breeding white clover varieties resistant to the virus, but also by selection at the symbiont level, seems worthy of investigation.

We are indebted to Professor P. T. Thomas, Director of the Welsh Plant Breeding Station, for facilities and helpful advice and criticism, to Dr G. ap Griffith for advising against determining soil-nitrogen content, Mrs E. Horzelska for help in preparing the manuscript and $\mathrm{Mr} \mathrm{H}$. Richards for the photograph. 


\section{REFERENCES}

ChiYkowski, L. N. (1962). Clover phyllody and strawberry green petal diseases caused by the same virus in Eastern Canada. Can. J. Bot. 40, 1615.

Frazier, N. W. \& PosnetTe, A. F. (1957). Transmission and host-range studies of strawberry greenpetal virus. Ann. appl. Biol. 45, 580 .

Fred, E. B., BALdwin, I. L. \& MCCoy, E. (1932). Root nodule bacteria and leguminous plants. Univ. Wisc. Stud. Sci. 5, 343.

Joshi, H. U., CARR, A. J. H. \& JoNes, D. G. (1967). Effect of clover phyllody virus on nodulation of white clover (Trifolium repens) by Rhizobium trifolii. J. gen. Microbiol. 47, 139.

NiCOL, H. \& THORNTON, H. G. (I942). Competition between related strains of nodule bacteria and its influence on infection of the legume host. Proc. R. Soc. B 130, 32.

Nutman, P.S. (1952). Studies on the physiology of nodule formation. III. Experiments on the excision of root tips and nodules. Ann. Bot. N.S. 16, 79.

Posnette, A. F. \& Ellenberger, C. E. (1963). Further studies of green-petal and other leafhoppertransmitted viruses infecting strawberry and clover. Ann. appl. Biol. 51, 69.

Vanderveken, J. (1964). Influence d'un virus sur la nodulation chez Trifolium repens. Annls. inst. Pasteur 107, I43.

\section{EXPLANATION OF PLATE}

Healthy seedling plants of the white clover variety S. Ioo immediately before harvest, growing in boxes of soil previously containing: top left, uninfected plants with effective w4 strain of Rhizobium trifolii; top right, uninfected with mixed effective $\mathrm{W} 4$ rhizobia and ineffective $\mathrm{w} 22$ rhizobia; bottom left, uninfected with ineffective w 22 rhizobia; bottom right, CPV-infected with effective w4 rhizobia. 


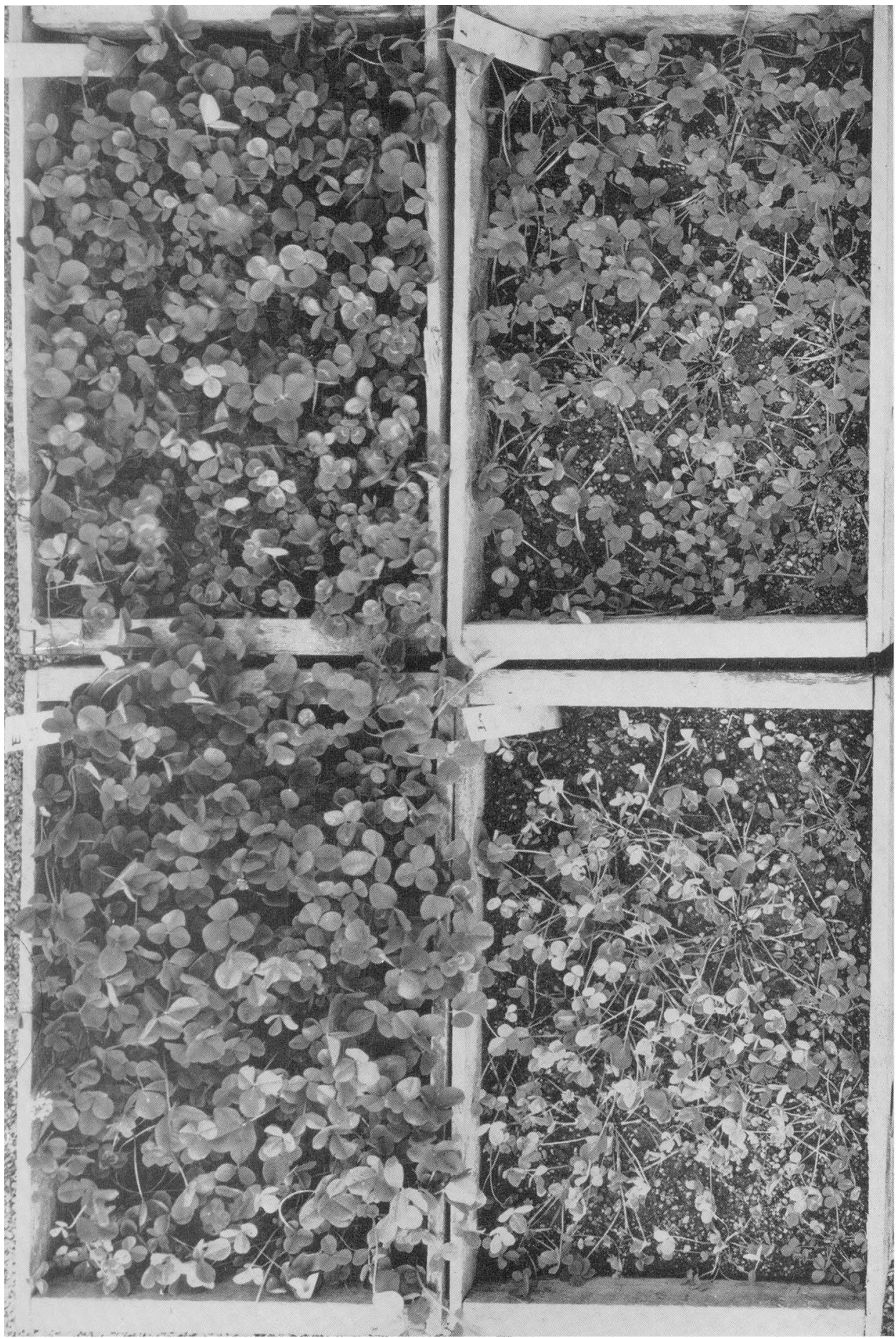

